\title{
Community health workers' involvement in mother- child care during the postpartum period in the Missed Opportunities in Mother and Infant Health (MOMI) project in the Kaya health district: a contribution analysis
}

Halima TOUGRI ( $\square$ tougrih@yahoo.com )

Institut de Recherche en Sciences de la Santé (IRSS) https://orcid.org/0000-0001-5080-5155

\section{Rachidatou Compaoré}

Institut de Recherche en Sciences de la Santé (IRSS)

\section{Adja Mariam Ouédraogo}

Institut de Recherche en Sciences de la Santé (IRSS)

\section{Bila Blandine}

Institut de Recherche en Sciences de la Sante (IRSS)

\section{Marleen Temmerman}

International Centre for Reproductive Health (ICRH)

\section{Seni Kouanda}

Institut de Recherche en Sciences de la Santé (IRSS)

\section{Research article}

Keywords: effect analysis, MOMI project, community participation, $\mathrm{CHWs}$

Posted Date: November 11th, 2019

DOI: https://doi.org/10.21203/rs.2.17115/v1

License: (c) (i) This work is licensed under a Creative Commons Attribution 4.0 International License.

Read Full License 


\section{Abstract}

Maternal and infant morbidity and mortality remain high in the world and particularly in sub-Saharan Africa. However, actions to strengthen postpartum care remain weak and are mainly limited to health facilities (HFs). The MOMI project implemented in the Kaya health district included community-based health workers (CHWs) in the care of women and children during the first postpartum year through home visits, accompanying mothers to HFs and outreach sessions. The aim of this study was to assess the contribution of CHWs to postpartum women's HF attendance.Methods We conducted an effect assessment using Mayne and Lemire's contribution analysis framework. This was a mixed-case study. Qualitative and quantitative data were collected through project document review and interviews.Results Out of 6633 women, 3768 (56.8\%) were visited by CHWs before the 10th day following childbirth, 34.3\% between the sixth and eighth week and $9 \%$ between the ninth and twelfth months; during the same home visit periods, the CHWs accompanied $57.3 \%, 51.4 \%$ and $32.5 \%$ of women, respectively, to HFs for postpartum consultations. Postpartum consultation rates within the first week postpartum increased from $29 \%$ in 2011 to $80 \%$ in 2015 and from 19\% to 50\% within 6 weeks.Conclusions Community-based health workers involvement in the care of women improved their adherence to postpartum consultations.

\section{Background}

Maternal and infant morbidity and mortality remain high in the world and particularly in sub-Saharan Africa. In 2015, the number of women who died from pregnancy or delivery complications was estimated at 303,000 [1].

Almost all maternal deaths (99\%) occur in developing countries, with over half of those in sub-Saharan Africa and 22\% in South Asia [1]. Sub-Saharan Africa has the highest maternal mortality rate (RMM), resulting in 546 maternal deaths per 100,000 live births. Indeed, out of the 40 countries in the world with the highest rates, 36 are from sub-Saharan Africa [1].

Although most maternal deaths occur between the third term of pregnancy and the first week after childbirth, women still face a high death risk beyond six weeks postpartum [2,3].

In 2013, in sub-Saharan Africa, $17.6 \%$ of maternal deaths occurred in the intrapartum period and within the 24 hours following delivery, $47.8 \%$ between 24 hours and the $42^{\text {nd }}$ day and $13.1 \%$ between the $43^{\text {rd }}$ day and a year after delivery [4].

Despite a clear pattern of mortality and morbidity during the postpartum period, actions to improve postpartum care remain poor and are mostly implemented at the health facility (HF) level, sometimes not including the communities [2].

However, since the Alma Ata conference, communities have been largely involved in the health systems in most developing countries. Community members, commonly referred to as community health workers (CHWs), along with health professionals, are involved in improving the population's health through drug 
distribution (Ivermectin, contraceptives) and management of certain community-related diseases (diarrhoea, pneumonia, malaria) [2].

Studies on community involvement in the improvement of maternal and child health in general, and specifically in the postpartum period, have already been conducted in several countries through different approaches [3-7].

Although studies are increasingly focusing on assessing the impact of health programmes, there are still few studies, particularly in Africa, specifically related to community-based interventions. Moreover, most of these evaluations typically use counterfactual elements or case-control studies to attribute a result to a given programme [8].

For complex interventions, however, it is often difficult to fully attribute the impact to the intervention [912]. It would therefore be interesting to determine the contribution of each component of an intervention or a programme to the achievement of the obtained results, in order to optimize and improve strategies for public health interventions [9]. Hence, our study aims to analyse the effect of the community component of the MOMI project in the Kaya health district by using a mechanistic approach rather than a counterfactual one.

The specific aims of this study are to analyse the contribution of $\mathrm{CHW}$ involvement in the achievement of the effect, in particular the attendance of HF in postpartum women; to identify the factors that have contributed to or limited women's access to postpartum health services; and to identify elements of the intervention that contributed to women's postpartum HF attendance.

\section{Methods}

\section{Study setting:}

The MOMI project was implemented in the Kaya health district in the Central-North region of Burkina Faso. The health district of Kaya covers 342 villages and seven urban areas. This district is centred on a regional hospital centre (CHR) with 60 health facilities, including 54 health and social promotion centres (CSPSs) and a central private medical centre with surgical satellite facilities (CMA).

At the community level, there are two CHWs per village, usually a man and a woman responsible for carrying out health promotion activities and malaria case management, diarrhoea, etc.

\section{Description of the MOMI project}

The Missed Opportunities in Maternal and Infant Health (MOMI) project is funded by the European Union and implemented in four African countries: Kenya, Malawi, Mozambique and Burkina Faso. In Burkina Faso, the project was implemented in 12 CSPSs in the health district of Kaya, including eight rural and four urban CSPSs. These 12 health facilities were selected based on the low rate of postpartum consultation and their location in the Kaya health demographic site (Kaya HDSS). The objective of the 
MOMI project at the community level was to improve maternal and child health through women's adherence to postpartum consultations. Through the involvement of the CHWs, the project aimed at increasing the rate of postpartum consultations in these 12 health facilities. These CHWs were the same individuals selected by the community and were already working in collaboration with health workers. However, because of the context, only female CHWs were implemented in the MOMI project activities.

The MOMI project included three intervention components selected through a participatory process. One intervention was implemented at the community level; specifically. the support of the mother-infant by the $\mathrm{CHWs}$ in the first year following delivery. The other two interventions were implemented at the health facility level - specifically, improved immediate postpartum care and integration of maternal and infant health services [13].

At the community level, each CHW had to carry out three home visits to any mother and infant in her coverage area during the first year following delivery. These home visits corresponded to the different periods of postpartum consultation or immunization at the health facility level. During these visits, the CHW had to take care of both mother and child, look for signs of danger and refer if necessary.

Depending on the visit time period, using a picture box, the CHW also carried out outreach sessions on the signs of danger, family planning, and the importance of postpartum consultations, etc. As much as possible, the $\mathrm{CHW}$ was to accompany the woman to the health facility for postpartum consultations.

The project was initiated in 2011 with a situational analysis. After the stakeholders were trained, the implementation of the community and health interventions began in September 2013 and ended in January 2016. Type of study

We carried out a case study using a mixed method approach (qualitative and quantitative). This study was conducted from June to September 2015 in four health facilities selected according to their localization and implementation degree (weak versus strong).

\section{Data collection and analysis}

We collected quantitative and qualitative data.

The quantitative data were collected before and after the intervention in the 12 health facilities as part of the MOMI project. The data sources included the tools put in place within the project framework: the ideogram, reference card, $\mathrm{CHW}$ diaries and monitoring file.

The qualitative data were collected through semi-structured interviews and document reviews. The interviews were conducted during a case study in four health centres in urban and rural areas. In each area, we selected two HFs, one with a weak implementation rate and another with a strong implementation rate. Policymakers and MOMI implementers (12 postpartum women, $12 \mathrm{CHWs}, 16 \mathrm{HFWs}$, 2 policymakers and $3 \mathrm{MOMI}$ team members) were interviewed (see Table 1). The data sources included supervision reports, policy advisory board (PAB) meeting minutes, stakeholder and community leader 
meeting minutes, the critical review of the policy report (Work package or WP2) [14], the situational analysis report (WP3) [15], the selection of interventions report (WP4) [13], and the event log.

The quantitative method measured the degree of implementation, and the qualitative method enabled us to assess the context and collect additional details on the degree of implementation through the document review and the interviews. Thus, by triangulation, the factors affecting the implementation, the alternative explanations and the elements of contribution were identified.

Concerning data analysis, the quantitative data were entered using Epi data and analysed with Excel 2007 and Stata 13 software. The interviews were first transcribed verbatim in French and then analysed using Nvivo 11 software. Content analysis was chosen as an analysis method.

\section{Theoretical framework}

For our evaluation, we used the six steps of the contribution analysis framework proposed by Mayne, combined with Lemire's framework, the Relevant Explanation Finder (REF) [16].

Based on the observation that the rates of postpartum consultations had increased since the introduction of the MOMI project interventions in the Kaya health district, we formulated the following cause-effect questions, which we would answer throughout the analysis (Steps 1-3):

- Did the involvement of the $\mathrm{CHW}$ in the care of women, and their children contribute to increasing the use of postpartum health services by women?

- which factors contributed to or limited the use of health services by women during the postpartum period?

- What aspects of the intervention have contributed?

To answer these questions, we retrospectively developed the theory of the intervention programme at the community level (Figure 1) and then tested the assumptions contained therein. We then used Lemire's framework, REF (steps 4 to 5), to examine the mechanisms of change and to understand the influencing factors and alternative explanations. The components of the REF are presented in Table 1.

To reinforce the plausibility of the results of the contribution evaluation, our analysis focused on the two main assumptions used in the REF.

\section{Results}

REF element analysis showed that there was a link between the activities of the project and the use of health services by women during the postpartum period. The analysis also showed that some factors contributed to, or on the contrary, limited women's access to health services; however, other factors might also explain the increase in the use of postpartum services. 


\section{Intervention activities carried out by the CHW}

The CHW carried out home visits, accompanied women to HFs for postpartum visits, conducted outreach sessions and referred to HFs the mothers/children who were showing signs of danger or mothers who delivered at home.

The CHW conducted three home visits with each woman and her baby during this period; the first one was before the tenth day from the delivery (D0-10), the second visit was between the sixth and the eighth weeks (W6-8) and the last visit was between the ninth and the twelfth months (M9-12).

These visit rates varied from by location, with $25 \%$ completed visits in CSPSs from sector 4 to $81 \%$ in the CSPS of Kalambaogo, and from month to month, with 29.3\% completed visits in September 2013 to $79.3 \%$ in July 2014 for D0-10 visits (Figure 3 ). During the same period, 57.3\% (3803/6633), 51.4\% (2056/3999) and $32.5 \%(342 / 1067)$ of women were accompanied in a health facility by the CHW following D6-10, W6-8 and M9-12 visits, respectively.

Outreach sessions were carried out in households, at HFs, during wedding or baptism ceremonies, or during any other activity involving a group of women.

\section{Women's attendance at health services}

The sixth day, consultation rates increased $80 \%$ from under $40 \%$ at the beginning of the intervention to $80 \%$ after, and the sixth week rates increased from under $20 \%$ to over $50 \%$ for all the health facilities. All of the participants interviewed in this case study acknowledged that the number of women who came to postpartum care, including those who gave birth at home, had significantly increased since the implementation of the project activities. The observations during supervision and the data collected during monitoring confirmed this assertion. In addition, health workers who were interviewed reported that the number of women who received postpartum consultations was higher on the sixth day than in the ninth month (Figure 4).

\section{Influencing factors}

Several factors have influenced women's access to health services during the implementation of the project's interventions.

As part of the facilitating factors, the participatory approach was adopted by the project for the selection of CHWs and their activities, their commitment, the involvement of community leaders, the collaboration of health workers, the non-financial motivation system and the influence of the other women.

- CHWs' commitment

The majority of $\mathrm{CHWs}(90.3 \%)$ conducted the activities until the end of the project. Their main motivation was the moral duty towards the community that had chosen them because they felt valued by this community. All the CHWs interviewed had a perfect understanding of their role and responsibility in the 
project. They had the conviction that their work had a positive impact on maternal and child health because they thought they were influencing women in the use of health services.

During the interviews, some of them expressed themselves as follows:

"I agreed to do this work because when the members of your community meet and choose you to entrust you with a responsibility, you have the duty to do it otherwise it will seem like you are not concerned about people's health." (CHW from a rural HF).

"It's for our well-being because health is priceless. And also, it is our village, and we have the duty to contribute to its development. If we are concerned about the development of our village, we must wholeheartedly support the well-being of the population. This is the reason for our involvement in contributing to the improvement of health." (CHW2, Rural HF)

- CHWs' motivation

The interviewed project team members reported that it was difficult to find an appropriate motivation mechanism. For this effect, the project opted for a non-financial motivation that included training, supervision and endowment. Thus, the $\mathrm{CHWs}$ received bicycles, and during each supervised session, meeting and training, they were compensated with a daily subsistence allowance and transportation fees. They received certificates of participation at the end of the project. This type of non-financial incentive had a mixed impact on the project implementation. In fact, it encouraged the majority of CHWs to carry out the activities, but it also resulted in the resignation of $9.7 \%$ of them. During supervision and interviews, a CHW from the urban area who left the project expressed herself:

"I warned you from the beginning that your volunteering story was not going to go far. Anyway, I am not visiting women anymore because we earn nothing in your project. I manage with my small business to feed my children and you want me to stop this and go visiting women with nothing in exchange?" (CHW, urban HF)

The majority of the $\mathrm{CHWs}$ positively appreciated the non-financial forms of motivation adopted by the project, such as training. In the case study, the interviewed $\mathrm{CHWs}$ reported that the training was beneficial because it strengthened their capacity regarding postpartum care and facilitated the use of the picture box during home visits.

"I believe that these capacity building trainings help us to face certain realities in the field. They help us to better conduct sensitizations in the field." (CHW 6, urban HF)

Regular supervision of the activities has improved the work of the CHWs in the field. Indeed, the CHWs were supervised one month after the training and then every three months until the end of the project. This supervision was led by the project team in collaboration with the Kaya health district management team. All the CHWs interviewed stated that they received regular supervision and found it to be beneficial because the supervisory team discussed with them the difficulties they encountered in the field and 
together they proposed solutions. Most CHWs considered these supervised sessions to be something that motivated them to continue their activities.

"They asked us about the difficulties encountered and the evolution of our activities. If there are aspects that we have forgotten, they remind us and exhort us to improve the work."(CHW 4, urban HF)

- CHWs' bridging role

The baseline study showed that women's acceptance of the CHW would depend on her reputation within the community and her collaboration with health workers. Via this relationship, the CHWs conducted home visits and outreach sessions. Data from the various interviews confirmed this assumption.

"Our CHW helps us a lot. Even at night, when a woman is in labour, she accompanies her to the HF without any hesitation. Sometimes she gets on her bike to follow (the woman) to the CSPS." (postpartum woman, rural HF)

The mutual trust between the $\mathrm{CHW}$ and her community, as well as the collaboration between the $\mathrm{CHW}$ and the formal health workers, made a bridge between the community and health services. The CHW was perceived as a real asset by the community and health services. The messages they conveyed were welcomed by women. The women interviewed described them as a benchmark for maternal health in the village and advocates for women in interactions with their husbands and health workers. Their presence broke down barriers such as fear and mistrust that some women might feel in the presence of a health worker.

The following statements collected during the interviews confirmed these facts:

"There are women who want to go to the HF, but they are afraid of health workers. But they say that if the CHW working with the health workers and accompanies them, they will no longer be afraid and will express themselves freely because the CHW is there."(ICP, urban HF)

- Involvement of community leaders

The involvement of community leaders and male CHWs facilitated the work of the CHWs in the field. Several CHWs interviewed reported that the community members consented to participate in their activities since the community leaders themselves were involved in the project. Thus, they had access to households for outreach sessions, and women were receptive.

"They [women] simply believed that it is for their benefit because an activity that village leaders and authorities are involved in can only be beneficial to the community. So, they consent as well." (CHW6, urban FS)

However, other factors have limited women's access to these services, such as geographical and financial accessibility (especially during the rainy season), and the weak decision-making power of women, especially in rural areas. Women, health workers and the CHWs interviewed confirmed these obstacles. 
"Here in the city there is no problem because women are autonomous. But in the villages, men decide where, when and how their wives can go. They decide whether their wives must go to the HF or not. Sometimes women or children can fall sick for more than a week, but they are waiting because their husbands did not give permission to go to consultation." (Health worker, urban HF)

During the monitored supervision sessions, the CHWs reported that some women did not come to postpartum consultations because of the cost of consumables.

"You know, madam, I will tell you the truth. Our women do not come on the 42nd day because your health workers asked them to pay for gloves, speculum, etc. So, if you do not have money and your husband also refuses to give you some, you have to stay home." (rural CHW)

\section{Alternative explanations}

The health services component of the MOMI project, the performance-based funding (PBF) and the Save the Children NGO's project called "Victoire sur la Malnutrition" (VIM) were alternative explanations.

Indeed, the health services component of MOMI advocated the integration of maternal and infant health care so that some health workers would include postpartum visits with mothers and their infants during immunization visits or healthy infant consultations. For example, in some health facilities, appointments for postpartum visits on the sixth day were scheduled at the same time as the child's BCG vaccination, and the sixth-week appointments were scheduled at the same time as the child's PENTA1 vaccination or healthy infant consultation appointment. In addition, within all the health facilities, the health worker keeps the mother's health record after delivery. The records were delivered only on the sixth postpartum day. An urban health worker said the following during supervision:

"Since we are keeping the health records, women come back, if only for their health records, and we seize this opportunity to treat them. But sometimes we are obliged to hand over the notebook before the consultation when the woman is not from the same location." (Supervision Report)

The PBF was funding some maternal health indicators, such as postpartum consultation rates. This led some health workers to become more involved in postpartum services. Their collaboration with the CHWs in the search for women who were absent at the various appointments was intensified.

The VIM project distributed food to pregnant and breastfeeding mothers in rural areas. This distribution was based on the mothers' adherence to prenatal consultations and the immunization schedule for children. Another influence of the VIM project may lie in the fact that some CHWs who worked in the MOMI project were also working on the VIM project. These CHWs took advantage of the food distribution incentive to sensitize women. These facts were corroborated by supervisory data and interviews.

"We also take advantage of the distribution of VIM to raise awareness on FP (family planning), the importance of meeting (health consultations) appointments, and signs of danger (for mother and child's 
health). We generally finish our sensitization before we start to share food; otherwise, women may leave." (Supervision Report)

\section{Assembling the performance story}

This is an iterative process of identifying elements of the intervention that contributed to increasing the attendance of health services by postpartum women. Among the causal links established in the theory of change, we believe that the participatory approach adopted by the MOMI project for the identification of the activities and the selection of the CHWs enabled the appropriation of the intervention by the different actors. The involvement of the community through male $\mathrm{CHWs}$ and community leaders helped boost female CHWs in their actions in the sense that they felt valued and considered. Regular training and supervision boosted the CHWs' self-esteem and confidence.

This perception of the importance of their role motivated them to carry out the project activities among women. These activities enabled women to become aware of the dangers that could arise after delivery and the importance of postpartum care at the health centre, which explained their agreement to attending postpartum health services.

However, of all the activities carried out, we believe that home visits and outreach sessions, as well as a good collaboration between health workers and $\mathrm{CHWs}$, contributed more to the attendance of health services by women.

On the other hand, the accompaniment of women to the HFs seemed to have a smaller contribution because this activity was not carried out by all the CHWs because of the lack of adapted means of transport: while the CHWs were riding a bicycle or were walking, the postpartum woman would ride a motorcycle or a bicycle.

\section{Discussion}

The limitations of our study were mainly related to the evaluation approach used, that is, the contribution analysis. How a contribution analysis-based approach can account for the "cause-effect" relationship remains controversial. However, the methodology used enabled us to collect high-quality data and reliable information that could raise questions for further research.

The benefit of the CA (contribution analysis) is that it focuses on examining contextual factors and other explanations that affect the success and outcomes of the programme.

During the implementation of the project, some $\mathrm{CHWs}$, mainly from urban areas, abandoned the activities. The main reasons for this were the absence of financial incentives and the unpleasant attitude of women in the city. Moreover, almost all of the resigning $\mathrm{CHWs}$ were not $\mathrm{CHWs}$ before the MOMI project implementation. They were young and were involved in income-generating activities. They also joined the project in the hopes to be paid. Studies conducted in Nepal and South Africa reported similar results. In Nepal, $5 \%$ of women annually leave the female voluntary $\mathrm{CHW}$ programme because of the lack of wages 
[17]. In South Africa, $22 \%$ of the tuberculosis programme dropped out due to a lack of interest and compensation[18].

Women in rural areas had a higher rate of home visits than women in urban areas. This situation in urban areas could be explained by the difficulties encountered by the CHWs in conducting home visits, particularly difficulties relating to their social status. Monica O. et al. found in a similar study in Uganda that the poor education level of community health workers negatively affected their activity in urban areas [19].

CHWs were selected by their community, and they represented the resource persons of the community in these locations. Therefore, they were motivated to help their community in matters of health. We found, as in the other MOMI project countries (Kenya, Malawi, Mozambique), that the trust between CHWs and their community motivated them to provide an effective bridging function [20]. However, CHWs were more respected and paid more attention to by the population in rural than the urban areas. This may explain the high rate of visits observed in rural areas. Other factors may also explain the high rate of visits, particularly the seniority of the CHWs, their advanced age and the dynamics of the voluntary CHWs in the health facility. In addition, older CHWs had no young children, were supported by their loved ones and were freer to provide home visits than young $\mathrm{CHWs}$.

We also found that the number of home visits decreased over time. The number was higher in the first postpartum week than in the sixth week and in the ninth month. The low rate of the ninth month visit was because the set of activities during this period mainly concerned family planning (FP); yet, postpartum women had already benefited from FP services and thus were possibly longer be interested in them.

Moreover, in some communities, talking about FP was difficult for $\mathrm{CHWs}$, and they generally preferred to limit visits in order to avoid problems. Community involvement in the selection of interventions and was significant in facilitating the work of community-based health workers within villages. This was also observed in other studies conducted in Asia and Africa [21-23].

One of the difficulties encountered in implementing the interventions at the community level was the financial incentive of the CHWs. It was very difficult to find the kind of motivation that would suit everyone. While some people were advocating fee-for-service, others opted for non-financial motivation such as being equipping with a bicycle. Studies conducted in Tanzania and South Africa have shown that while money was an incentive, non-financial learning incentives were favoured [17,22,24]. Meta-analyses on the method of payment of the CHWs showed that it was hard to find a fair method of payment [22]. However, in 2016, the MOH decided to motivate the CHW with 60 USD (30 000 XOF per month).

Several CHWs stated that the recognition of the community was their main source of motivation. This has also been observed in several studies conducted in Nepal, Gambia and Ethiopia [17,22,24]. Other motivational factors, such as acquiring some experience, moral duty towards their community, and hope for being rewarded, were reported by $\mathrm{CHWs}$ in our study. Studies conducted in South Africa reported these facts as well [18].

Page $11 / 21$ 


\section{Conclusion}

The involvement of $\mathrm{CHWs}$ in the management of women during the postpartum period contributed to increasing the attendance of these women in health facilities. Several factors helped achieve these results, including the non-financial motivation system. However, although the system adopted by the MOMI project did not have a negative impact on the majority of CHWs, it should be noted that it is difficult to continuously work without being paid in a context of poverty. It is time to find a permanent mechanism to motivate CHWs or find other adapted interventions to ensure the sustainability of interventions involving the community. This could involve the pooling of resources and the integration of the various activities of the different NGOs working in the field with the same CHWs.

\section{List Of Abbreviations}

CA: contribution analysis

CHR: regional hospital centre

CHWs: community-based health workers

CMA: medical centre with surgical satellite facilities

CSPS: health and social promotion centres

D0-10: before the tenth day from the delivery

FP: family planning

HF: health facility

M9-12: between the ninth and the twelfth months

MOMI: Missed Opportunities in Mother and Infant Health

PBF: performance-based funding

REF: Relevant Explanation Finder

RMM: Maternal mortality rate

VIM: Victoire sur la Malnutrition

W6-8: between the sixth and the eighth weeks

\section{Declarations}


- Ethics approval and consent to participate

The study received the approval of Ethics Committee for Research in Health of Burkina Faso under the deliberation number: 2015-5-074. This committee belongs to the health ministry. We obtained written informed consent and guaranteed the confidentiality of all participants prior to the interviews.

- Consent for publication

Not applicable

- Availability of data and material

The datasets used and/or analysed during the current study are available from the corresponding author on reasonable request.

- Competing interests

The authors declare that they have no competing interests

- Funding

The research leading to these results has received funding from the European Community's Seventh Framework Programme (FP7/2007-2013) under grant agreement no. 265448. We also received grant from WHO/HUB for financing our Master of Public Health training.

- Authors' contributions

HT supervised the intervention, collected the data, performed the analyses and drafted the paper. SK obtained funding for the study. RC, AMO, BB and MT reviewed the paper and SK completed it in collaboration with all authors who read and approved the final version of the manuscript.

- Acknowledgements

We thank the European Union for funding this research (European Community's Seventh Framework Programme (FP7/2007-2013)). We also thank the WHO/HUB for financing our Master of Public Health training at the Institut Africain de Santé publique (IASP).

- Authors' information

1. Institut de recherche en sciences de la santé (IRSS)

2. Institut africain de santé publique

3. ICRH, the International Centre for Reproductive Health, with offices at Ghent University 


\section{References}

1. Organization WH. Trends in maternal mortality: 1990-2015: estimates from WHO, UNICEF, UNFPA, World Bank Group and the United Nations Population Division. 2015;

2. Duysburgh E, Kerstens B, Kouanda S, Kaboré CP, Belemsaga Yugbare D, Gichangi P, et al. Opportunities to improve postpartum care for mothers and infants: design of context-specific packages of postpartum interventions in rural districts in four sub-Saharan African countries. BMC Pregnancy Childbirth. 2015 Dec;15(1).

3. Lewycka S, Mwansambo C, Rosato M, Kazembe P, Phiri T, Mganga A, et al. Effect of women's groups and volunteer peer counselling on rates of mortality, morbidity, and health behaviours in mothers and children in rural Malawi (MaiMwana): a factorial, cluster-randomised controlled trial. Lancet (London, England). 2013 May;381(9879):1721-35.

4. Nair N, Tripathy P, Costello A, Prost A. Mobilizing women's groups for improved maternal and newborn health: evidence for impact, and challenges for sustainability and scale up. Int J Gynaecol Obstet. 2012 Oct;119 Suppl 1:S22-25.

5. Nair N, Tripathy P, Sachdev HS, Bhattacharyya S, Gope R, Gagrai S, et al. Participatory women's groups and counselling through home visits to improve child growth in rural eastern India: protocol for a cluster randomised controlled trial. BMC Public Health. 2015;15(1):384.

6. Prost A, Colbourn T, Seward N, Azad K, Coomarasamy A, Copas A, et al. Women's groups practising participatory learning and action to improve maternal and newborn health in low-resource settings: a systematic review and meta-analysis. Lancet (London, England). 2013 May;381(9879):1736-46.

7. Koblinsky M. Community-based Postpartum Care: an urgent unmet need. Washington DC, USA: USAID, The CATALYST Consortium; 2005. In Washington DC, USA: USAID; 2005. (The CATALYST Consortium).

8. C. STOCKS-RANKIN. Reflective Literature Review of Contribution Analysis. IRISS; 2014.

9. Mayne J. Addressing attribution through contribution analysis: using performance measures sensibly. Can J Progr Eval. 2001;16(1):1.

10. Approches d'évaluation axées sur la théorie concepts et pratiques. Ottawa: Secrétariat du Conseil du Trésor du Canada; 2012.

11. Chen H-T. Theory-driven evaluations. Newbury Park, CA. In: Sage Publications Inc. 1990.

12. Weiss CH. Theory-based evaluation: Past, present, and future. New Dir Eval. 1997;1997(76):41-55.

13. IRSS M. MOMI - Missed Opportunities in Maternal and Infant health, WP4: Design optimum package of postpartum interventions and services tailored to conditions at each site: Selected Package of Interventions for Each MOMI Study Site. 2013. ??

14. Mann S. Cross country analysis of maternal newborn and child health policies in Burkina Faso, Kenya, Malawi and Mozambique. European Commission FP7 MOMI project. 2013.

15. Barros, H., Lopes SC. Cross country situation analysis of maternal and newborn care in Burkina Faso, Kenya, Malawi and Mozambique. European Commission FP7 MOMI project. 2013. ??? 
16. Mayne J. Contribution analysis: An approach to exploring cause and effect. 2008;

17. Glenton C, Scheel IB, Pradhan S, Lewin S, Hodgins S, Shrestha V. The female community health volunteer programme in Nepal: decision makers' perceptions of volunteerism, payment and other incentives. Soc Sci Med. 2010 Jun;70(12):1920-7.

18. Kironde S, Klaasen S. What motivates lay volunteers in high burden but resource-limited tuberculosis control programmes? Perceptions from the Northern Cape province, South Africa. Int J Tuberc Lung Dis Off $\mathrm{J}$ Int Union Against Tuberc Lung Dis. 2002 Feb;6(2):104-10.

19. Okuga M, Kemigisa M, Namutamba S, Namazzi G, Waiswa P. Engaging community health workers in maternal and newborn care in eastern Uganda. Glob Health Action [Internet]. 2015;8:23968. Available from: http://www.ncbi.nlm.nih.gov/pubmed/25843491

20. Djellouli N, Mann S, Nambiar B, Meireles P, Miranda D, Barros H, et al. Improving postpartum care delivery and uptake by implementing context- specific interventions in four countries in Africa: a realist evaluation of the Missed Opportunities in Maternal and Infant Health ( MOMI) project. BMJ Glob Health 2017;2:e000408. doi:10.1136/ bmjgh-2017-000408

21. Bhutta ZA, Soofi S, Cousens S, Mohammad S, Memon ZA, Ali I, et al. Improvement of perinatal and newborn care in rural Pakistan through community-based strategies: a cluster-randomised effectiveness trial. Lancet (London, England). 2011 Jan;377(9763):403-12.

22. Amare Y. Non-Financial Incentives for Voluntary Community Health Workers: a Qualitative Study [Internet]. JSI Research \& Training Institute. 2009. Available from: files/367/Non-Financial Incentives for Voluntary Community Health Workers FINAL.pdf

23. Haines A, Sanders D, Lehmann U, Rowe AK, Lawn JE, Jan S, et al. Achieving child survival goals: potential contribution of community health workers. Lancet (London, England) [Internet]. 2007;369(9579):2121-31. Available from: http://www.ncbi.nlm.nih.gov/pubmed/17586307

24. Nyanzi S, Manneh $H$, Walraven $G$. Traditional birth attendants in rural Gambia: beyond health to social cohesion. Afr J Reprod Health [Internet]. 2007;11(1):43-56. Available from: http://www.ncbi.nlm.nih.gov/pubmed/17982947

\section{Tables}

Table 1: Relevant Explanation Finder (REF) 


\begin{tabular}{|c|c|c|c|c|c|c|c|c|}
\hline \multirow[t]{2}{*}{ Mechanism } & \multirow{2}{*}{$\begin{array}{l}\text { Influencing } \\
\text { factors/Alternative } \\
\text { explanations }\end{array}$} & \multirow[t]{2}{*}{ Type of rival } & \multirow[t]{2}{*}{ Level } & \multicolumn{5}{|c|}{ Degree of influence } \\
\hline & & & & Certainty & Robustness & Range & Prevalence & Evidence \\
\hline $\begin{array}{l}\text { Promotion } \\
\text { activities led } \\
\text { by CHWs } \\
\text { boost their } \\
\text { trust in the } \\
\text { role they are } \\
\text { playing for } \\
\text { the } \\
\text { improvement } \\
\text { of PPCs }\end{array}$ & $\begin{array}{l}\text { The participatory } \\
\text { approach used by the } \\
\text { project to select } \\
\text { interventions and CHWs }\end{array}$ & Primary rival & Structural & High & High & High & High & High \\
\hline $\begin{array}{l}\text { CHW support } \\
\text { systems } \\
\text { such as } \\
\text { trainings, } \\
\text { supervision } \\
\text { and non- } \\
\text { financial } \\
\text { incentives } \\
\text { build their } \\
\text { capacities } \\
\text { and } \\
\text { encourage } \\
\text { them to } \\
\text { carry on their } \\
\text { activities. }\end{array}$ & $\begin{array}{l}\text { The adherence of } \mathrm{CHWs} \\
\text { and health workers to } \\
\text { the project strategy }\end{array}$ & Primary rival & Individual & High & High & High & High & High \\
\hline \multirow[t]{2}{*}{$\begin{array}{l}\text { The CHW is } \\
\text { a community } \\
\text { member; } \\
\text { therefore, } \\
\text { she can } \\
\text { easily } \\
\text { conduct } \\
\text { home visits, } \\
\text { and advise, } \\
\text { she can be } \\
\text { more } \\
\text { trustworthy, } \\
\text { and she can } \\
\text { serve as link } \\
\text { between the } \\
\text { community } \\
\text { and health } \\
\text { facilities }\end{array}$} & $\begin{array}{l}\text { Collaboration between } \\
\text { CHWs and health } \\
\text { workers }\end{array}$ & Primary rival & Interpersonal & High & High & High & High & High \\
\hline & $\begin{array}{l}\text { Motivation system } \\
\text { adopted by the project }\end{array}$ & $\begin{array}{l}\text { Commingled } \\
\text { rival }\end{array}$ & Individual & Medium & High & Medium & Medium & High \\
\hline
\end{tabular}

Page 16/21 


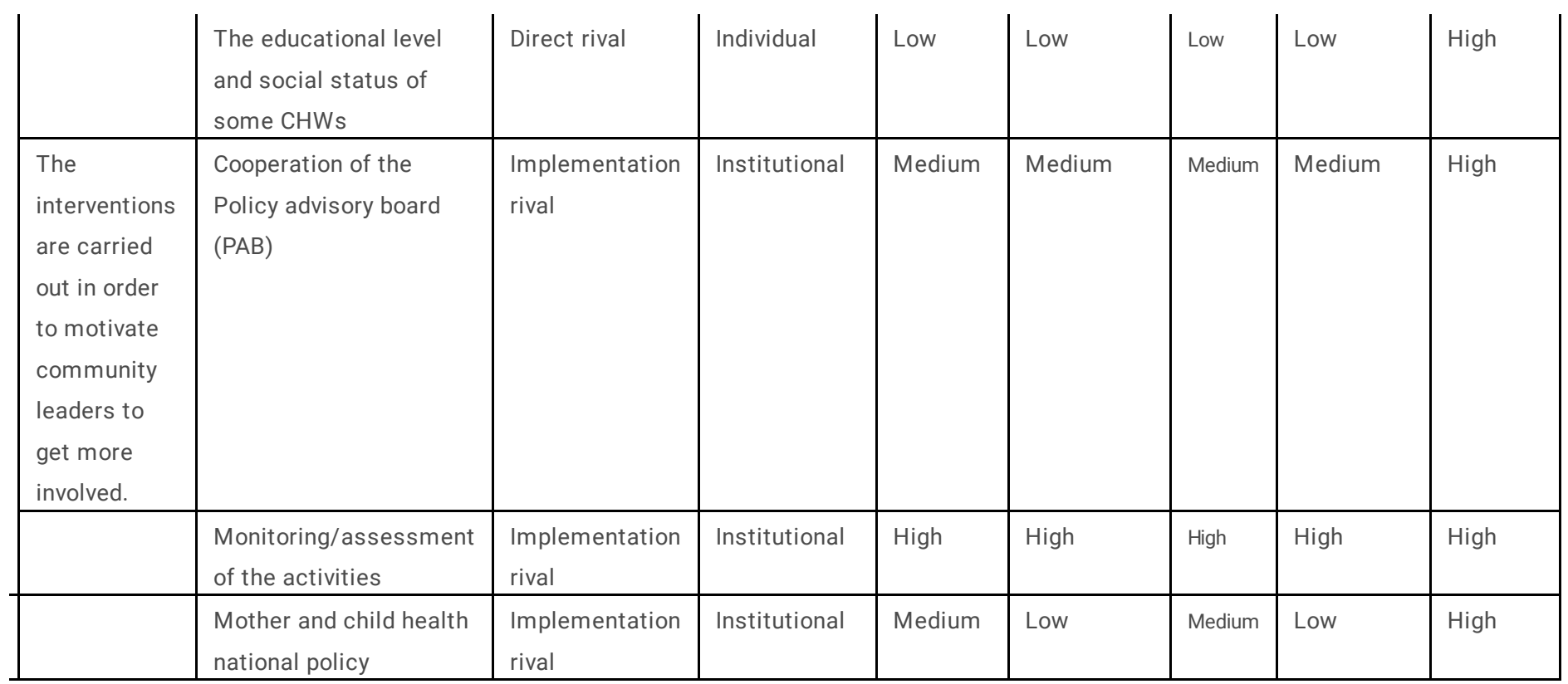




\begin{tabular}{|c|c|c|c|c|c|c|c|c|c|}
\hline & & & & & Certainty & Robustness & Range & Prevalence & Evidence \\
\hline \multirow[t]{6}{*}{$\begin{array}{l}\text { e } \\
\text { e } \\
\text { ie } \\
\text { y } \\
\text { id } \\
\text { ions. }\end{array}$} & \multirow{2}{*}{$\begin{array}{l}\text { The CHW } \\
\text { represents a } \\
\text { link between } \\
\text { the } \\
\text { community } \\
\text { and health } \\
\text { service, } \\
\text { which helps } \\
\text { remove } \\
\text { barriers such } \\
\text { as fear and } \\
\text { suspicion of } \\
\text { the } \\
\text { community } \\
\text { towards } \\
\text { health } \\
\text { workers. }\end{array}$} & $\begin{array}{l}\text { Postpartum } \\
\text { women's } \\
\text { attitude, } \\
\text { enthusiasm } \\
\text { and interest } \\
\text { in } \\
\text { postpartum } \\
\text { care }\end{array}$ & Primary rival & Individual & High & High & High & High & High \\
\hline & & $\begin{array}{l}\text { Trust } \\
\text { between the } \\
\text { CHWs and } \\
\text { women }\end{array}$ & Primary rival & Individual & High & High & High & High & High \\
\hline & $\begin{array}{l}\text { Women's } \\
\text { adherence } \\
\text { depends on } \\
\text { their } \\
\text { husbands or } \\
\text { their } \\
\text { mothers-in- } \\
\text { law. }\end{array}$ & $\begin{array}{l}\text { Weak } \\
\text { decision- } \\
\text { making } \\
\text { power of } \\
\text { women } \\
\text { mainly in } \\
\text { rural areas }\end{array}$ & Primary rival & Institutional & Medium & Medium & Medium & Medium & Medium \\
\hline & $\begin{array}{l}\text { Behavioural } \\
\text { change is } \\
\text { adopted } \\
\text { when } \\
\text { postpartum } \\
\text { care is } \\
\text { promoted } \\
\text { within the } \\
\text { community. }\end{array}$ & $\begin{array}{l}\text { The low } \\
\text { purchasing } \\
\text { power of } \\
\text { some women } \\
\text { represents a } \\
\text { financial } \\
\text { barrier }\end{array}$ & $\begin{array}{l}\text { Implementation } \\
\text { rival }\end{array}$ & Individual & Medium & Medium & Low & Low & Medium \\
\hline & $\begin{array}{l}\text { Women who } \\
\text { were } \\
\text { supported by } \\
\text { CHWs share } \\
\text { their } \\
\text { experience } \\
\text { with other } \\
\text { women. }\end{array}$ & $\begin{array}{l}\text { Peer-to-peer } \\
\text { education }\end{array}$ & $\begin{array}{l}\text { Implementation } \\
\text { rival }\end{array}$ & Individual & High & Medium & Medium & Medium & High \\
\hline & $\begin{array}{l}\text { Men are } \\
\text { more } \\
\text { receptive to } \\
\text { men's or }\end{array}$ & $\begin{array}{l}\text { Involvement } \\
\text { of the } \\
\text { community } \\
\text { through }\end{array}$ & $\begin{array}{l}\text { Implementation } \\
\text { rival }\end{array}$ & Institutional & High & Medium & Medium & Medium & High \\
\hline
\end{tabular}

Page 18/21 


\begin{tabular}{|c|c|c|c|c|c|c|c|c|}
\hline $\begin{array}{l}\text { leaders' } \\
\text { messages }\end{array}$ & $\begin{array}{l}\text { community } \\
\text { leaders and } \\
\text { male CHWs }\end{array}$ & & & & & & & \\
\hline \multirow[t]{3}{*}{$\begin{array}{l}\text { The } \\
\text { attendance } \\
\text { at health } \\
\text { facilities can } \\
\text { be motivated } \\
\text { by other } \\
\text { interventions. }\end{array}$} & $\begin{array}{l}\text { HF } \\
\text { component } \\
\text { with inclusion } \\
\text { of care for } \\
\text { mother and } \\
\text { child. }\end{array}$ & $\begin{array}{l}\text { Implementation } \\
\text { rival }\end{array}$ & Institutional & High & High & Medium & Medium & High \\
\hline & $\begin{array}{l}\text { PBF with } \\
\text { more } \\
\text { involvement } \\
\text { of health } \\
\text { workers }\end{array}$ & $\begin{array}{l}\text { Implementation } \\
\text { rival }\end{array}$ & Institutional & Medium & Medium & Medium & Medium & High \\
\hline & $\begin{array}{l}\text { Food } \\
\text { distribution } \\
\text { by the project } \\
\text { VIM to } \\
\text { women who } \\
\text { attend HF } \\
\text { appointments }\end{array}$ & $\begin{array}{l}\text { Implementation } \\
\text { rival }\end{array}$ & Institutional & High & Medium & Medium & Medium & Medium \\
\hline
\end{tabular}

\section{Figures}

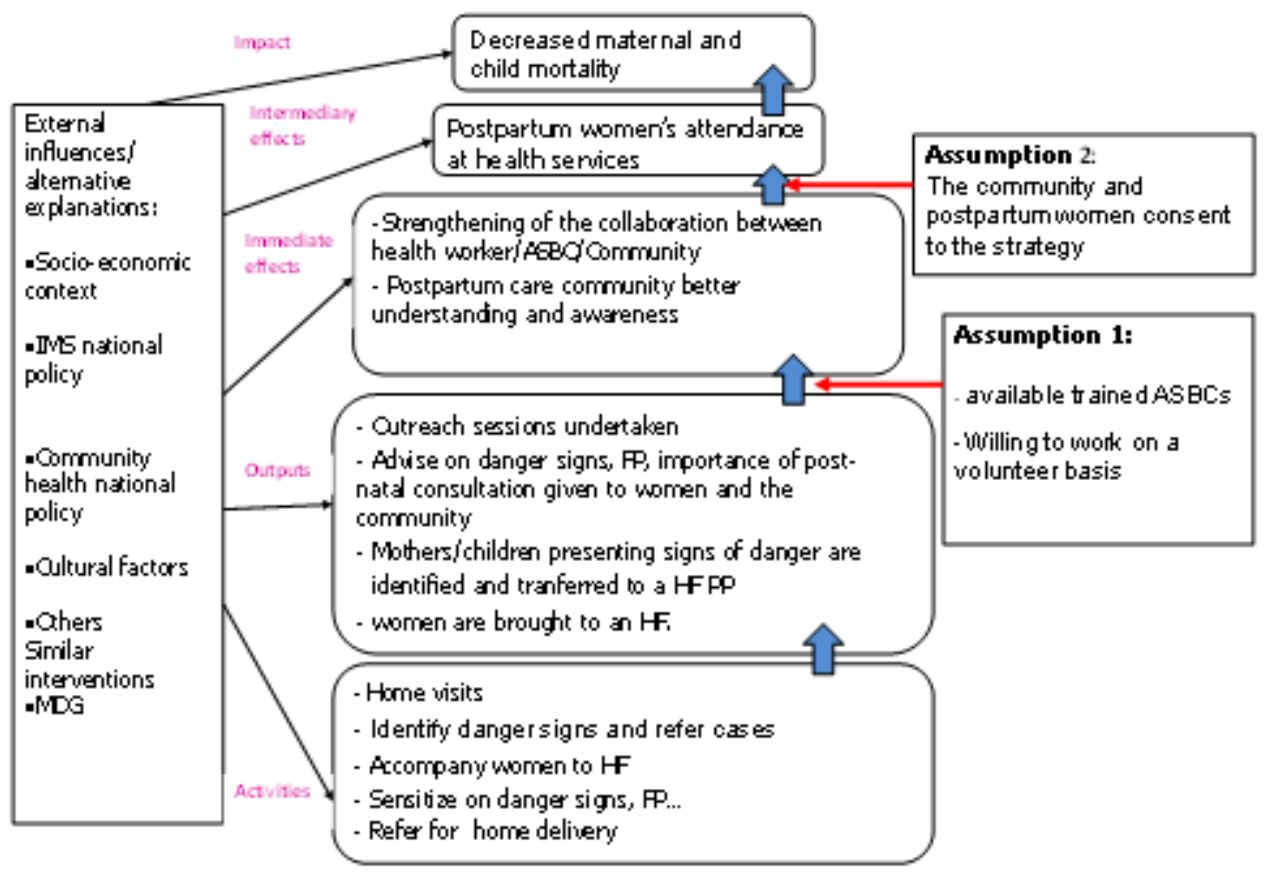

\section{Figure 1}




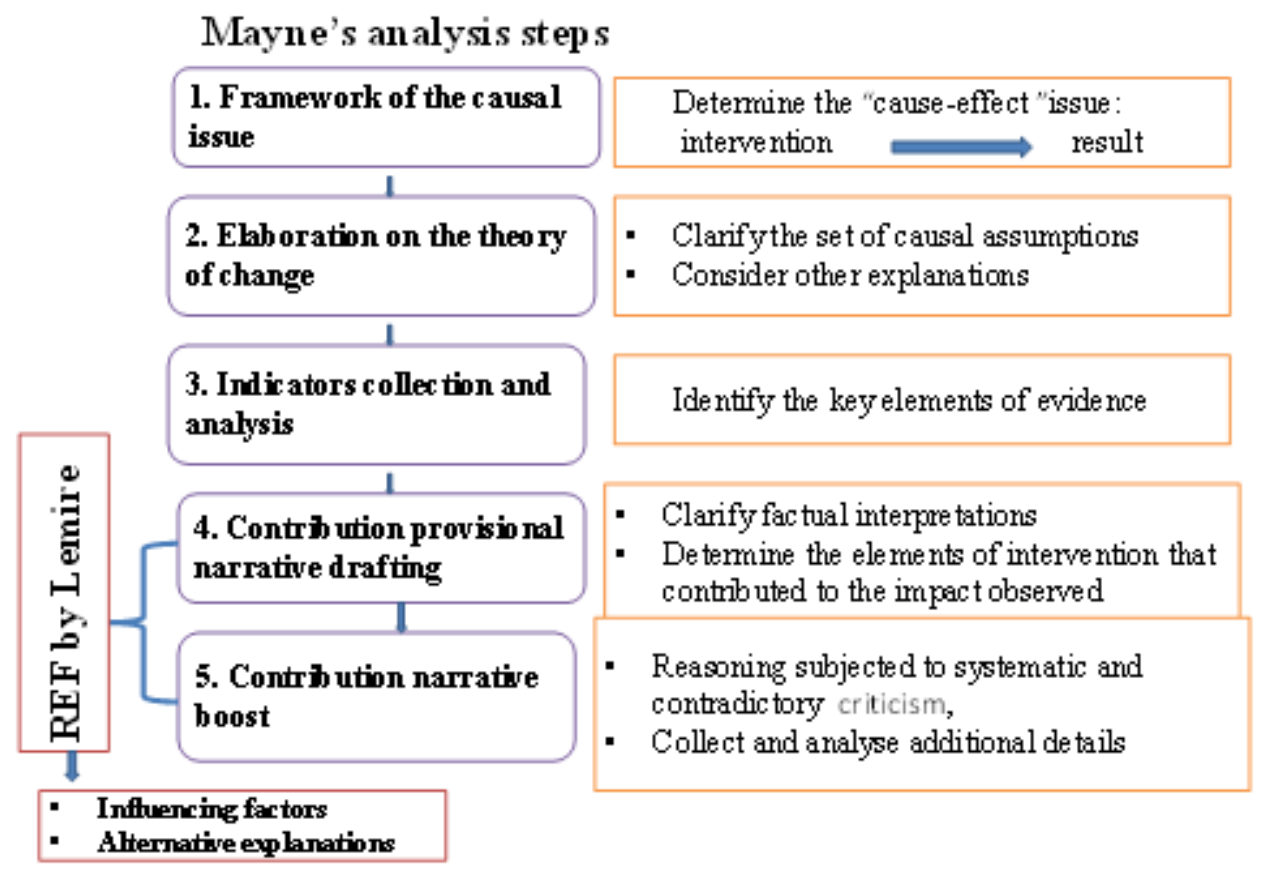

Figure 2

Conceptual framework: contribution analysis

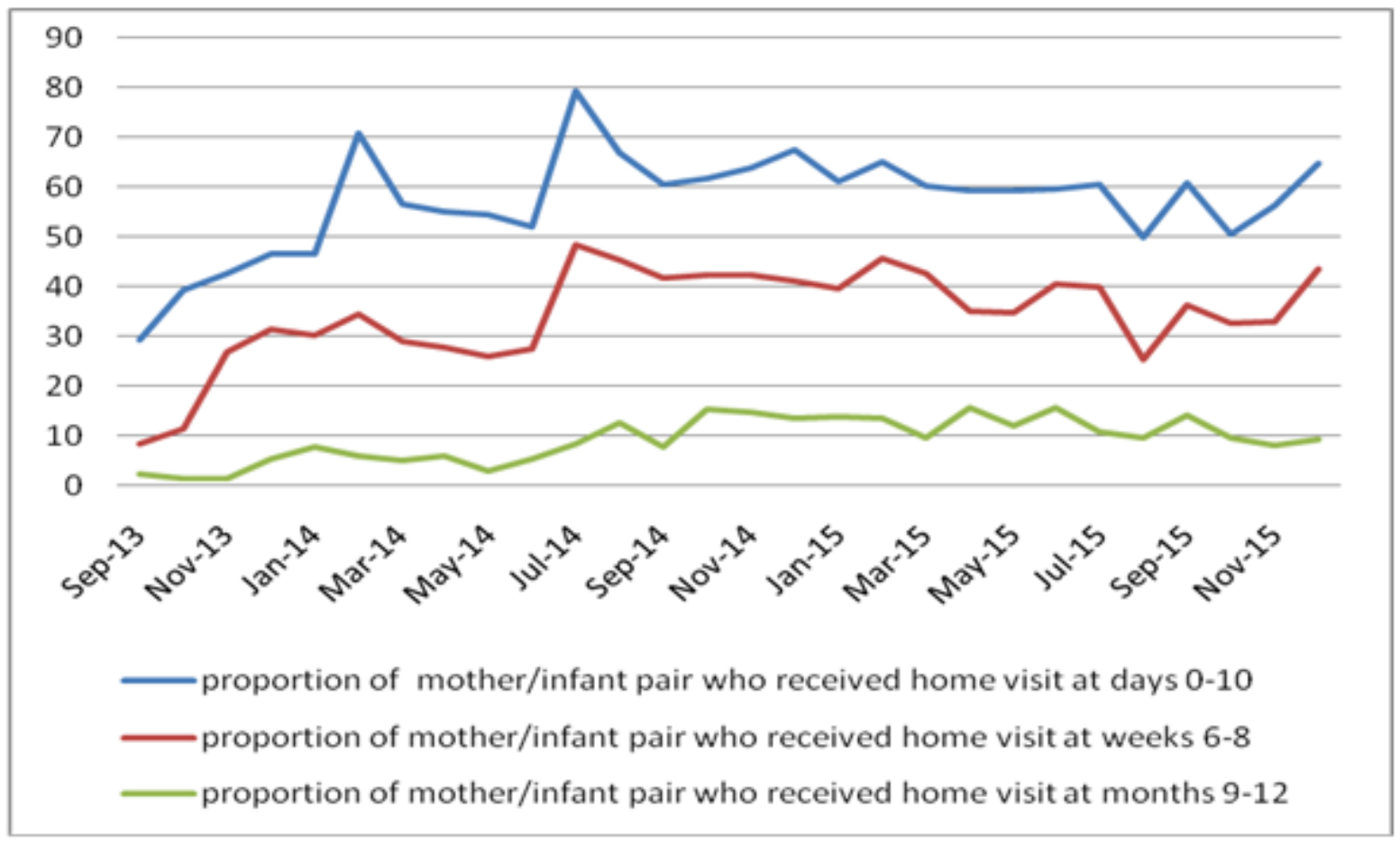

\section{Figure 3}

Home visit evolution per month from September 2013 to December 2015 


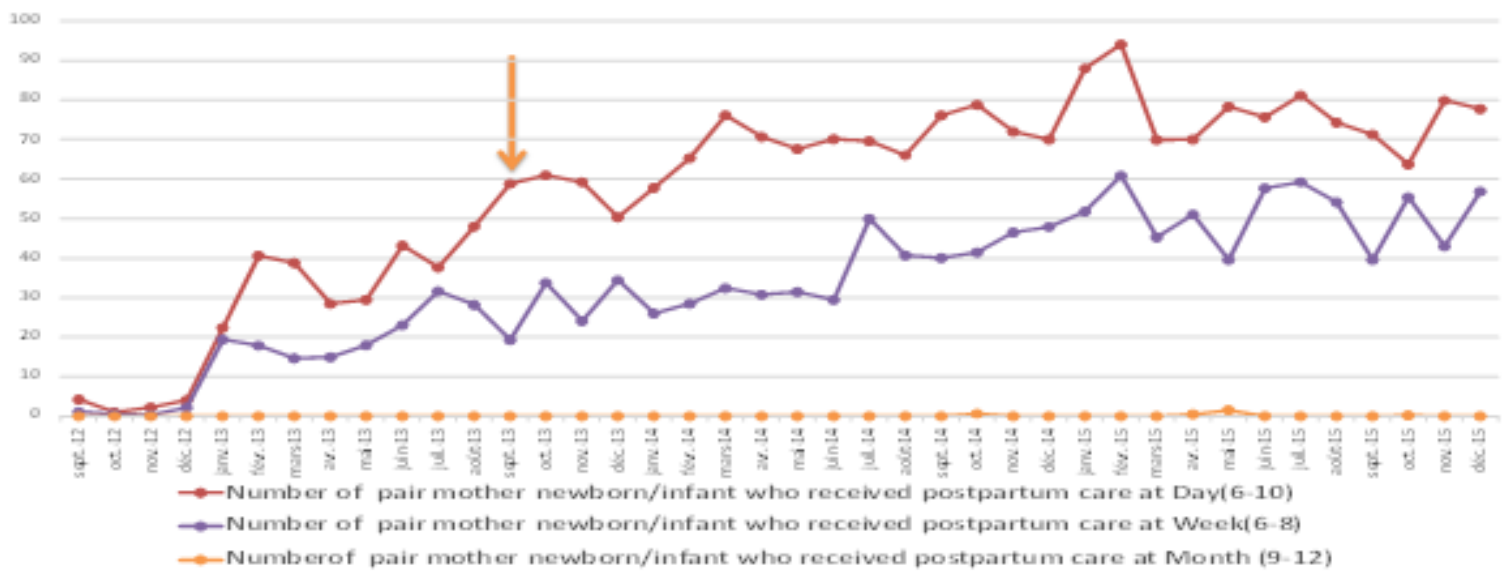

\section{Figure 4}

Postpartum care indicators before and after the intervention 